\title{
Evaluation of Physiological Properties of Winged Bean Rhizobium and Its Comparison with Other Rhizobia
}

\author{
Shweta Kumari ${ }^{*}$, R.C. Yadav ${ }^{1}$ and M.N. Jha ${ }^{2}$ \\ ${ }^{1}$ Department of Soil Science, ${ }^{2}$ Department of Microbiology, Dr. RPCAU, \\ Pusa, Bihar-848125, India \\ *Corresponding author
}

\begin{tabular}{|c|}
\hline $\begin{array}{l}\text { K e y w o r d s } \\
\text { Rhizobium, } \\
\text { Antibiotic, IAA, } \\
\text { pH, Winged bean }\end{array}$ \\
\hline Article Info \\
\hline $\begin{array}{l}\text { Accepted: } \\
26 \text { March } 2018 \\
\text { Available Online: } \\
10 \text { April } 2018\end{array}$ \\
\hline
\end{tabular}

A B S T R A C T

\section{Introduction}

Rhizobium species are soil bacteria, which display symbiotic interaction with specific legume hosts and most of these are sensitive to fluctuations in the quality and quantity of chemicals in the rhizosphere and hence affect the growth and productivity of whole plant (Miller and Wood, 1996). Most crops are sensitive to relatively high levels of salinity and acidity. In the case of legumes, there are additional problems because it is not only the plants but also the symbiotic Rhizobium bacteria, which are sensitive or act differentially both at the free-living stage as well as during the symbiotic relationship (Lloret et al., 1995). Rhizobium species appear to be varying in their symbiotic efficiency under acidic or alkaline conditions (Ali et al., 2009). Extreme $\mathrm{pH}$ affects nodulation by reducing infection by rhizobia. Highly acidic soils and highly alkaline soils $(\mathrm{pH}<4.0, \mathrm{pH}$ 
>8.0) affect survival, the growth of both partners, and thus reduce nitrogen fixation (Bordeleau and Prévost, 1994). The effect of varying $\mathrm{pH}$ levels on the growth of Rhizobium sp. in pure culture and Rhizobium inoculated plants have been recorded by some workers (Elizabeth et al., 2000). Rhizobia are known to produce significant levels of IAA both in free living conditions and also symbiotically in nodules (Ernstsen et al., 1987). Indole acetic acid (IAA) is one of the most physiologically active auxins. The majority of rhizobial strain (74\%) associated with different crop could produce IAA (Halda-Aliza, 2003). Indole acetic acid helps in the production of longer roots with increased number of root hairs and root laterals which are involved in nutrient uptake (Datta and Basu, 2000). The Rhizobium is also known to possess resistance or susceptibility towards known antibiotic substances (Prasuna, 2014). Resistance of nodule-forming bacteria (rhizobia) refers to their intrinsic resistance to antibiotics in terms of normal growth. Hartman and Amarger (1991) and Tas et al., (1996) emphasized the intrinsic resistance of different rhizobial strains to antibiotics as a significant phenotypic characteristic. A broad variation regarding susceptibility of individual rhizobial strains to antibiotics was found with respect to different rhizobial species.

\section{Materials and Methods}

An experiment was conducted in the Department of Soil Science, Dr. Rajendra Prasad Central Agricultural University, Pusa, Bihar during 2014-15 to evaluate physiological properties of Rhizobium isolated from winged bean, pea, gram, lentil and moong.

\section{Growth at different $\mathrm{pH}$}

Tolerance to change in $\mathrm{pH}$ was evaluated in terms of rhizobial growth. An equal aliquote (40ml) of pre-sterilized YEM broth was taken in six different $100 \mathrm{ml}$ conical flasks. $\mathrm{pH}$ of the broth was adjusted to 4.0, 5.0, 6.0, 7.0, 8.0 and 9.0 with the help of $0.5 \mathrm{M} \mathrm{NaOH}$ or $\mathrm{HCl}$ wherever required. An equal volume of liquid culture (1.2ml @3\%) of Rhizobium was added to each flask and was incubated at $25-30^{\circ} \mathrm{C}$. Separate sets were employed for all five different isolated rhizobia (winged bean, pea, gram, lentil and moong). Growth was measured in terms of optical density at $620 \mathrm{~nm}$ after 24, 48 and 72hrs. After 72hrs., content of each flask was centrifuged at 10,000rpm for $10 \mathrm{~min}$. Supernatant was used to measure change in $\mathrm{pH}$ of the medium due to rhizobial growth(Mensah et al., 2006).

\section{IAA production by Rhizobium}

Production of indole acetic acid (IAA) was estimated following the method suggested by Ehmann, 1977. A loop full of Rhizobium culture was inoculated in $25 \mathrm{ml}$ of Luria Berteni (LB) broth (tryptone, $\mathrm{NaCl}$ and yeast extract @10, 10 and $5 \mathrm{gl}^{-1}$ ) amended with $50 \mu \mathrm{gml}^{-1}$ tryptophan. Inoculated medium was incubated at $30 \pm 2^{\circ} \mathrm{C}$ in rotatory shaker for 24 , 48 and $72 \mathrm{hrs}$. Thereafter the content of conical flask was centrifuged at 10,000 rpm for $15 \mathrm{~min}$. Two $\mathrm{ml}$ of supernatant was taken in culture tubes, 2-3 drops of O-phosphoric acid and 4ml of Salkowski reagent containing $1 \mathrm{ml}$ of $0.5 \mathrm{M}$ $\mathrm{FeCl}_{3}$ in $50 \mathrm{ml}$ of $35 \% \mathrm{HClO}_{4}$ was added; left for $30 \mathrm{~min}$. in dark at room temperature and absorbance was recorded at 530nm. Auxin was quantified by preparing a calibration curve $\left(10-100 \mu \mathrm{g} \mathrm{ml}^{-1}\right)$ using IAA as standard.

\section{Antibiotic resistance test}

The susceptibility or resistance of rhizobia to an antibiotic was assayed with the help of antibiotic disc, a method adopted by Cole and Elksan (1979). After plating and solidification of the YEM agar medium on Petri plates, $0.1 \mathrm{ml}$ of bacterial suspension culture was 
spreaded allover YEM agar surface. Antibiotic impregnated bio-discs were placed on the surface of solidified medium. The antibiotic discs (HiMedia) used were of amoxyclav

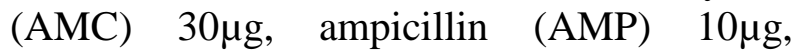
azithromycin (AZM) 15 $\mu \mathrm{g}$, chloramphenicol

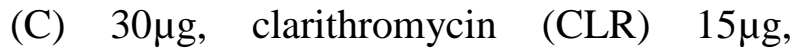
erythromycin (E) $15 \mu \mathrm{g}$, gentamycin (GEN) $10 \mu \mathrm{g}$, kanamycin $(\mathrm{K}) 30 \mu \mathrm{g}$, nalidixic acid (NA) 30 $\mathrm{g}, \quad$ streptomycin (S) $10 \mu \mathrm{g}$,

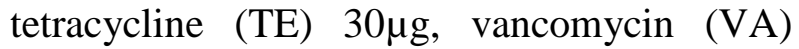
$30 \mu \mathrm{g}$. The Petri plates were then incubated at $30 \pm 2^{\circ} \mathrm{C}$ for $48 \mathrm{hrs}$. to observe the growth of rhizobia. Resistance to an antibiotic was detected by the formation of inhibition zone around the antibiotic discs used which was measured with the help of a scale.

\section{Results and Discussion}

Effect of $\mathrm{pH}$ on growth of rhizobial strain isolated from leguminous crops viz., winged bean, pea, gram, lentil and moong, IAA production ability and antibiotic susceptibility of these rhizobial strain were presented and discussed in the present study.

\section{pH tolerance}

Growth of winged bean Rhizobium along with pea, gram, lentil and moong rhizobia at different $\mathrm{pH}$ ranging from 4.0 to 9.0 recorded at 24, 48 and $72 \mathrm{hrs}$ in term of optical density are presented in (Table 1 and Fig. 1-3). The study showed all tested rhizobia a wide diversity in tolerance to their growth at different $\mathrm{pH}$. However rhizobia in general, followed a similar trend towards $\mathrm{pH}$ tolerance in term of growth measured as optical density (OD). Their growth was superior around neutral $\mathrm{pH}$. Least growth was recorded at $\mathrm{pH}$ 4.0 and an increase in growth was observed up to neutral $\mathrm{pH}$ i.e., $\mathrm{pH} 7.0$ but thereafter decreased at $\mathrm{pH}$ as high as $\mathrm{pH}$ 9.0. This might be related to less saline nature of the soil from which the isolates were recovered. Such observations were also made by many workers at different institutions time to time. In a study of rhizobial strains isolated from root nodules of chickpea carried out by Maatallah et.al., (2002) showed 90 to 100 per cent of isolates to grow in lightly acid and neutral $\mathrm{pH}$ as also observed in present study. In an another study carried at North Ethiopia by Keneni et al., (2010) revealed that native rhizobial strains were able to survive well in the various soil adjusted to $\mathrm{pH} 4.0$ up to 7.0, while the exotic strains were unable to survive $\mathrm{pH}$ up to 5.5 of the soil. Findings of work done by Jida and Assefa (2011) is in support to our study where they found that all thirty isolated lentil nodulating rhizobial isolates were ability to grow mildly in YEMA medium set at $\mathrm{pH}$ value 5.5 to neutral and slightly alkaline $\mathrm{pH}$ (8.0). Also at low $\mathrm{pH}, 26.7$ per cent of the isolates exhibited an acid tolerant character whereas only 13.3 per cent of isolates grew at $\mathrm{pH} 8.5$ and none of the isolates grew at $\mathrm{pH}$ 9.0. Bacterial strains (Rhizobium) isolated from root nodules of gram also showed similar growth response with respect to different $\mathrm{pH}$ adjusted growth medium in a study carried by Gauri et al., (2012). Also, growth was increased with increase in incubation period viz., from 24 to $72 \mathrm{hrs}$ irrespective of $\mathrm{pH}$. In case of winged bean Rhizobium growth in terms of OD was found least (0.759) at $\mathrm{pH} 4.0$ while the highest OD (1.069) was recorded at $\mathrm{pH} 7.0$ after $24 \mathrm{hrs}$ of incubation whereas at $72 \mathrm{hrs}$, OD was 1.168 at $\mathrm{pH} 4.0$ while it was 1.452 at $\mathrm{pH} 7.0$. Isolates grew at lowest $\mathrm{pH}$ 4.0indicating high level of tolerance to acid conditions. Alkaline $\mathrm{pH}$ has also a little antagonistic effect on growth of isolates as they grew at $\mathrm{pH}$ 9.0. The result of the effects of different $\mathrm{pH}$ values on the growth of Rhizobium species in culture shows that the Rhizobium strains grew well at $\mathrm{pH}$ values of between 6.0-8.0 with optimal growth density at $\mathrm{pH} 7.0$ in accordance with Mensah et al., 2006, who recorded the optimum $\mathrm{pH}$ of growth of Rhizobium is between 6.0 and 7.0. 
Table.1 Effect of varying growth medium $\mathrm{pH}$ on growth of rhizobia

\begin{tabular}{|c|c|c|c|c|c|c|c|c|c|c|c|c|c|c|c|}
\hline \multirow{2}{*}{ pH Rhizobia } & \multicolumn{5}{|c|}{24 hrs. } & \multicolumn{5}{|c|}{48 hrs. } & \multicolumn{5}{|c|}{72 hrs. } \\
\hline & WB & $\mathrm{P}$ & G & L & M & WB & $\mathrm{P}$ & G & $\mathrm{L}$ & M & WB & $\mathrm{P}$ & $\mathrm{G}$ & $\mathrm{L}$ & M \\
\hline 4.0 & 0.76 & 0.66 & 0.50 & 0.65 & 0.39 & 1.06 & 1.08 & 0.95 & 0.83 & 0.78 & 1.17 & 1.20 & 0.93 & 1.04 & 1.01 \\
\hline 5.0 & 0.88 & 0.79 & 0.52 & 0.70 & 0.67 & 1.20 & 1.12 & 0.98 & 1.04 & 1.13 & 1.21 & 1.37 & 0.95 & 1.11 & 1.29 \\
\hline 6.0 & 0.93 & 0.99 & 0.56 & 0.70 & 0.80 & 1.24 & 1.32 & 1.16 & 1.06 & 1.29 & 1.26 & 1.50 & 1.46 & 1.14 & 1.33 \\
\hline 7.0 & 1.07 & 1.11 & 0.68 & 0.75 & 0.92 & 1.32 & 1.49 & 1.46 & 1.20 & 1.40 & 1.45 & 1.52 & 1.60 & 1.39 & 1.56 \\
\hline 8.0 & 1.01 & 1.10 & 0.61 & 0.74 & 0.82 & 1.29 & 1.42 & 1.21 & 1.20 & 1.36 & 1.30 & 1.50 & 1.59 & 1.32 & 1.43 \\
\hline 9.0 & 0.98 & 1.09 & 0.58 & 0.71 & 0.81 & 1.26 & 1.21 & 1.00 & 1.13 & 1.34 & 1.27 & 1.30 & 1.01 & 1.23 & 1.42 \\
\hline
\end{tabular}

WB: Winged bean; P: Pea; G: Gram; L: Lentil; M: Moong

Table.2 Effect of different rhizobial growth on growth medium $\mathrm{pH}$

\begin{tabular}{|c|c|c|c|c|c|c|c|c|c|c|}
\hline \multirow{2}{*}{ pH Rhizobia } & \multicolumn{5}{|c|}{ Change in pH } & \multicolumn{5}{|c|}{$\%$ increase or decrease in $\mathrm{pH}$} \\
\hline & WB & $\mathrm{P}$ & G & L & M & WB & $\mathrm{P}$ & $\mathrm{G}$ & $\mathrm{L}$ & M \\
\hline 4.0 & 4.94 & 4.89 & 5.17 & 4.84 & 4.18 & 24 & 22 & 29 & 21 & 5 \\
\hline 5.0 & 5.91 & 5.58 & 5.99 & 5.95 & 5.02 & 18 & 12 & 20 & 19 & 0.4 \\
\hline 6.0 & 6.23 & 6.17 & 6.45 & 6.48 & 5.58 & 4 & 3 & 8 & 8 & -7 \\
\hline$\overline{7.0}$ & 6.97 & 6.95 & 6.90 & 6.99 & 6.36 & -0.4 & -0.7 & -1.4 & -0.1 & -9 \\
\hline 8.0 & 7.05 & 6.68 & 6.93 & 7.04 & 5.08 & -12 & -17 & -13 & -12 & -36 \\
\hline 9.0 & 7.28 & 7.22 & 7.26 & 7.27 & 4.67 & -19 & -20 & -19 & -19 & -48 \\
\hline
\end{tabular}

WB: Winged bean; P: Pea; G: Gram; L: Lentil; M: Moong

Table.3 IAA $\left(\mu \mathrm{g} \mathrm{ml}^{-1}\right)$ production during growth of five different rhizobia

\begin{tabular}{|c|c|c|c|}
\hline Rhizobia & $\mathbf{2 4}$ hrs. & $\mathbf{4 8}$ hrs. & $\mathbf{7 2 ~ h r s . ~}$ \\
\hline Winged bean & 53.2 & 58.5 & 64.6 \\
\hline Pea & 35.0 & 44.4 & 53.5 \\
\hline Gram & 32.4 & 45.5 & 57.0 \\
\hline Lentil & 44.3 & 47.0 & 50.2 \\
\hline Moong & 28.5 & 35.2 & 43.6 \\
\hline
\end{tabular}

Table.4 Effect of antibiotics on susceptibility or resistance of different rhizobia

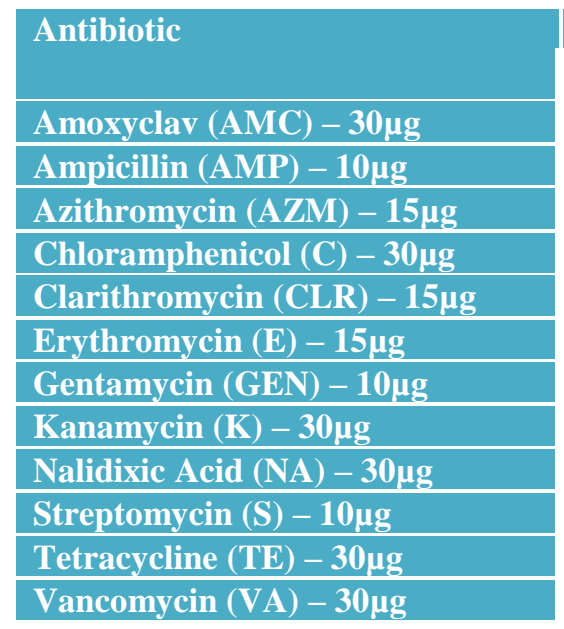

\begin{tabular}{|c|c|c|c|c|}
\hline \multicolumn{7}{|c|}{ Zone of inhibition $(\mathbf{m m})$} \\
\hline Winged bean & Pea & Gram & Lentil & Moong \\
\hline 20 & 12 & 25 & 17 & 20 \\
\hline 16 & $-(\mathrm{r})$ & 22 & 16 & $-(\mathrm{r})$ \\
\hline 16 & 34 & 14 & 16 & 28 \\
\hline 14 & 20 & $-(\mathrm{r})$ & 16 & 14 \\
\hline 16 & 25 & $-(\mathrm{r})$ & 13 & 26 \\
\hline 15 & 25 & 16 & 18 & 30 \\
\hline 13 & 18 & 28 & 14 & 17 \\
\hline 12 & 18 & 18 & 14 & 14 \\
\hline 22 & $-(\mathrm{r})$ & 14 & 18 & $-(\mathrm{r})$ \\
\hline 12 & 16 & 16 & 14 & 18 \\
\hline 20 & 30 & 32 & 22 & 36 \\
\hline$-(\mathrm{r})$ & 16 & 17 & $-(\mathrm{r})$ & 18 \\
\hline
\end{tabular}



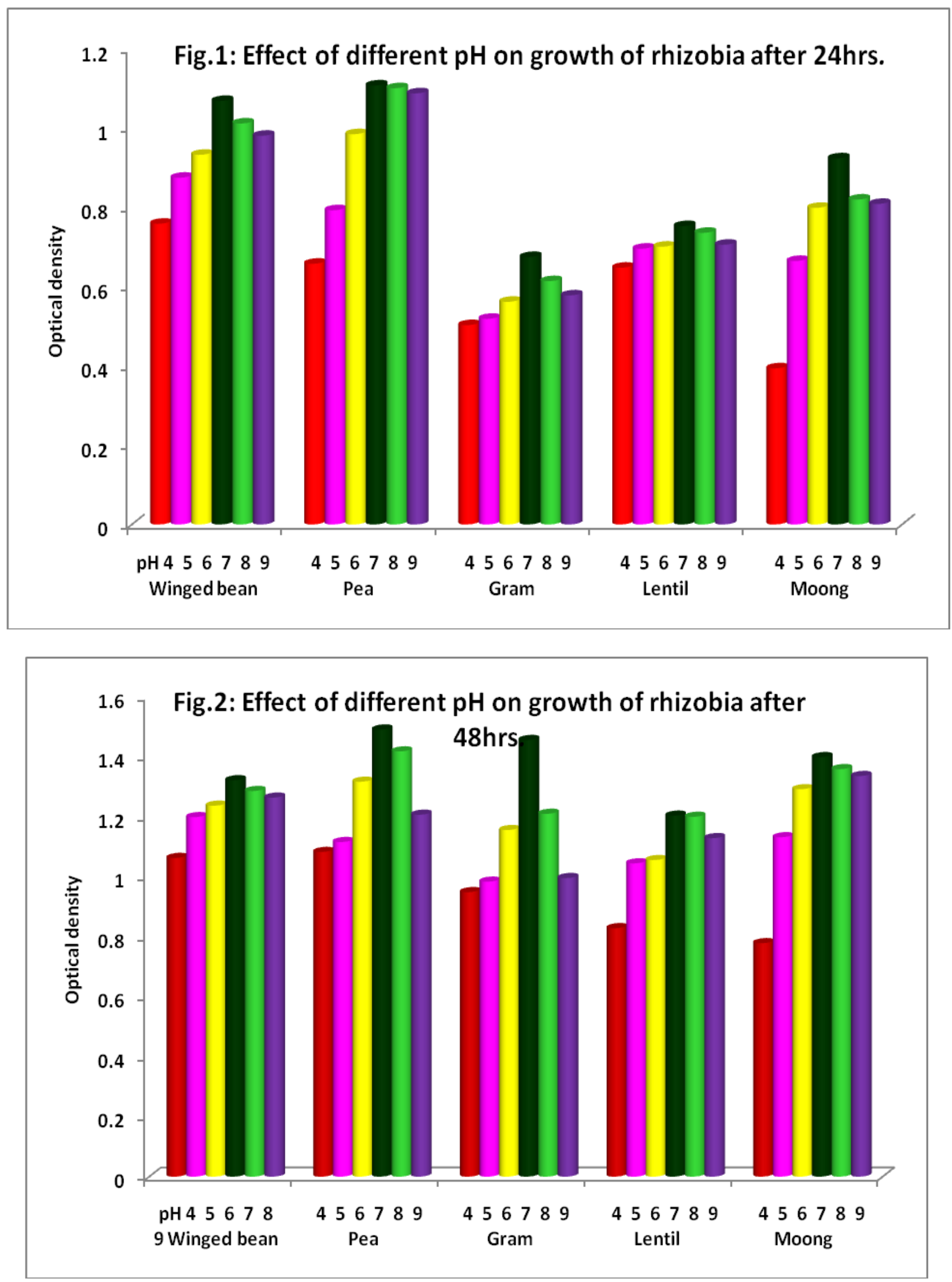

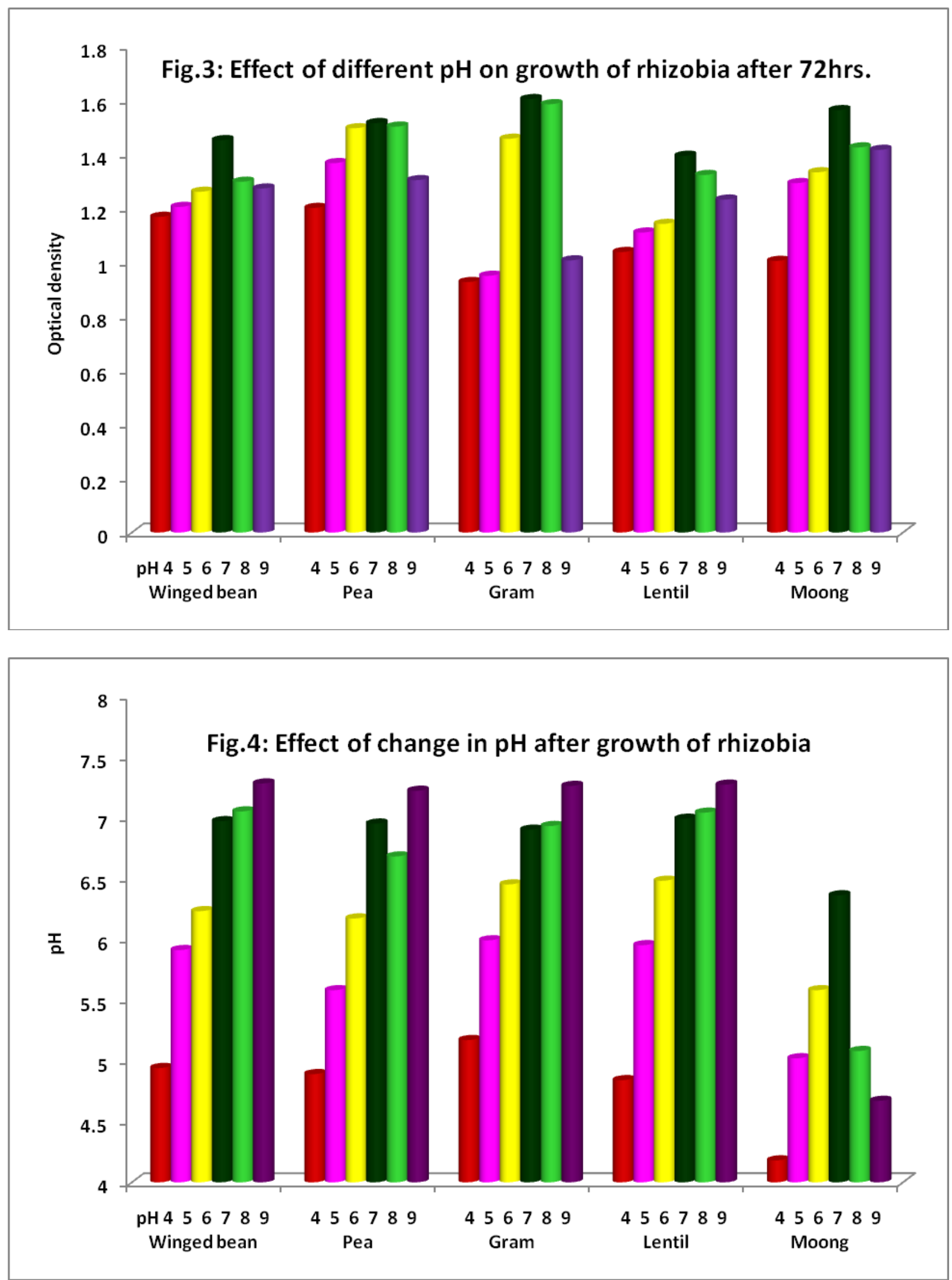

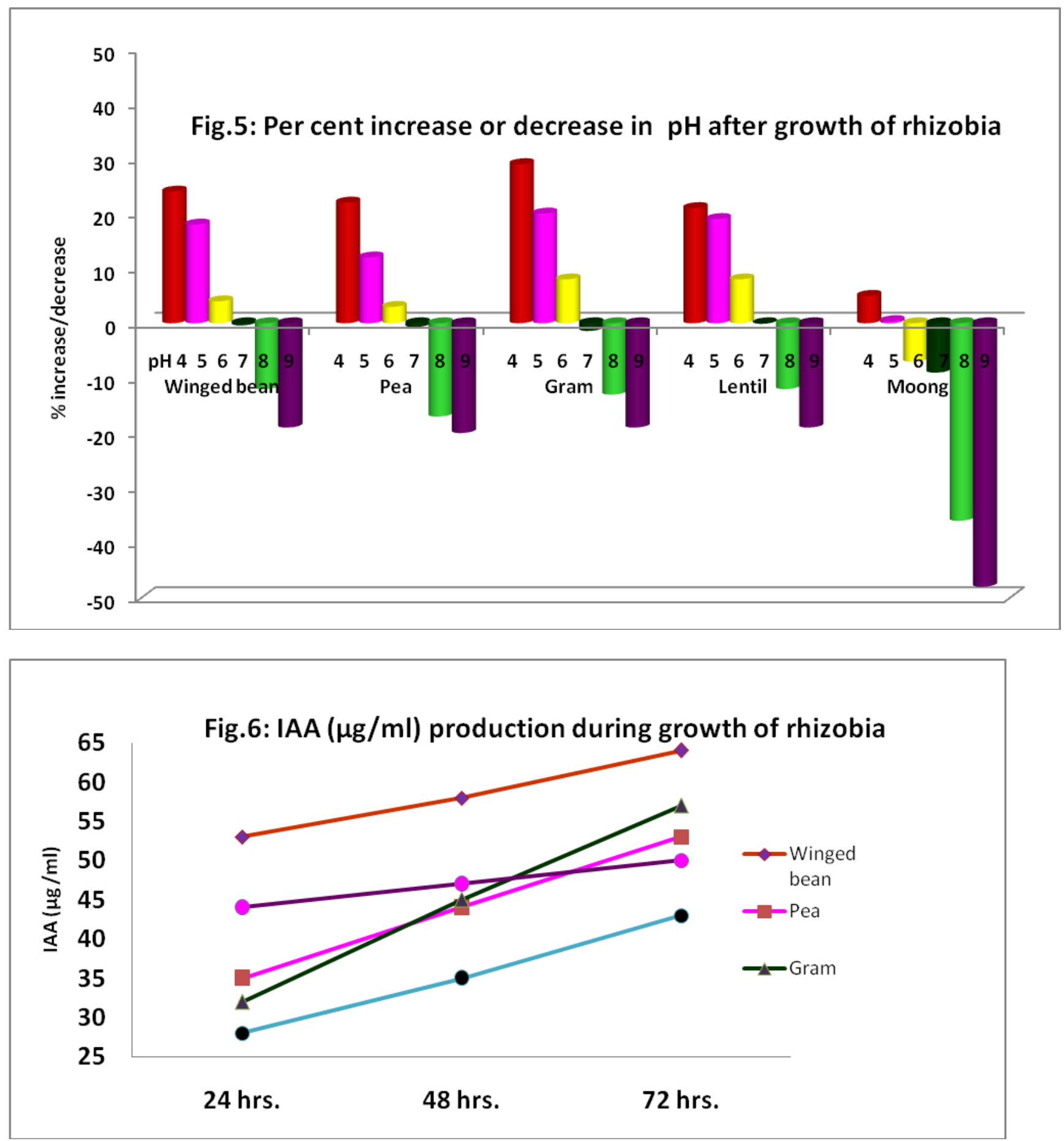

Tolerance to alkaline $\mathrm{pH}$ could be related to the calcareous and dry soils from which these isolates were isolated. Growth of different isolated rhizobia grown in YEM broth medium adjusted at varying $\mathrm{pH}$ under the study either positively or negatively influenced the change of $\mathrm{pH}$ value (Table 2 and Fig. 4-5). The per cent increase or decrease in original $\mathrm{pH}$ of the broth due to growth of rhizobia was maximum at extremity i.e., at $\mathrm{pH} 4.0$ or 9.0 and minimum at neutral. Maximum increase (29\%) in $\mathrm{pH}$ (from 9.0 to 5.17) was observed due to growth of gram Rhizobium while maximum 
decrease $(48 \%$ ) in $\mathrm{pH}$ (from 9.0 to 4.67 ) was observed due to growth of moong Rhizobium. Least increase $(3 \%)$ and decrease $(0.1 \%)$ in $\mathrm{pH}$ (from 6.0 to 6.17 and from 7.0 to 6.99 ) were recorded by growth of pea and lentil rhizobia respectively. However, moong showed better adaptability in $\mathrm{pH}$ between 5.0 and 7.0. Investigation carried out by different workers on Rhizobium isolated from root nodules of different crop viz., Rhizobium trifolii, $R$. phaseoli, $R$. leguminosarum and Bradyhizobium japonicum revealed the fact close to observation made in the present study (Bhatt et al., 2013; Dutta et al., 2015; Rai and Sen, 2015 and Kapembwa et al., 2016).

\section{IAA production}

The IAA (indole acetic acid) production by Rhizobium isolated from two winged bean germplasm along with four other Rhizobium isolated from legumenous crop viz., pea, gram, lentil and moong were shown in Table 3. In this study, all the five Rhizobium isolates were found to produce IAA from 24 to $72 \mathrm{hrs}$ after inoculation in LB media amended with L-tryptophane. Rhizobia produce significant levels of IAA both in free living conditions and also symbiotically in nodules (Ernstsen $e t$ al., 1987). Indole acetic acid (IAA) is one of the most physiologically active auxins. The majority of rhizobial strain $(74 \%)$ associated with different crop could produce IAA (Halda-Aliza, 2003). Indole acetic acid helps in the production of longer roots with increased number of root hairs and root laterals which are involved in nutrient uptake (Datta and Basu, 2000). The IAA production increased gradually with increase in incubation period from 24 to $72 \mathrm{hrs}$. i.e., its production was maximum at stationary phase of growth i.e., at 72hrs (Fig. 6). Among the rhizobial isolates studied, a maximum of 64.6 $\mu \mathrm{g} \mathrm{ml}^{-1}$ of IAA by winged bean isolate and least of $43.6 \mu \mathrm{g} \mathrm{ml}^{-1}$ in case of moong isolate was produced at $72 \mathrm{hrs}$ of incubation. Jida and
Assefa (2011) also determined IAA production by 30 rhizobial strains isolated from lentil and found that 36.7 per cent of them were able to produce IAA. All the isolates under present study produced varying concentration of IAA with a gradual increasing trend noticed from 24 to $72 \mathrm{hrs}$. Similar observation were also reported for isolates from moong (Kumar and Ram, 2012; Satyanandum et al., 2013 and Rajput and Panwar, 2013; pea (Kucuk and Cevkeri, 2016) and faba bean (Othman and Tamini, 2016). Kumar and Ram (2016) observed that all the strains of rhizobia isolated from moong crop produced maximum amount of IAA when isolates grown in YEMA medium supplemented with L-tryptophan. They also reported that Agrobacterium sp. produced more IAA than Rhizobium sp. Dutta et al., (2015) also proposed a view that IAA production increased with increase in incubation period from $24 \mathrm{hrs}$ and reached maximum at $72 \mathrm{hrs}$ in general irrespective of rhizobial isolates. This could be due to better utilization of medium components for IAA production by winged bean isolate compared to other Rhizobium isolate under study. Auxin production by rhizobia is often considered to improve growth and $\mathrm{N}_{2}$-fixation in many legumes including beans, lentil, chickpea and pea (Yanni, 1992; Huang and Erickson, 2007; Anjun et al., 2011; Zafar-ul-Hye et al., 2013).

\section{Antibiotics resistance}

The Rhizobium is known to possess resistance or susceptibility towards known antibiotic substances (Gray and Fitch 1983, Trieo-cuot et al., 1987). Varying degree of susceptibility to twelve different antibiotics were observed against all five rhizobia in terms of inhibition zone $(\mathrm{mm})$ is tabulated in Table 4 . Out of five different rhizobia, winged bean and lentil rhizobia were resistant to only one antibiotic

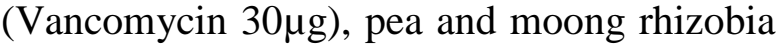
were resistant to two antibiotics (Ampicillin 
$10 \mu \mathrm{g}$ and Nalidixic acid $30 \mu \mathrm{g}$ ) while gram Rhizobium was observed to be resistant to

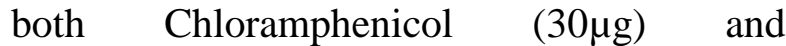
Clarithromycin $(15 \mu \mathrm{g})$. The results from work of Milicic et al., (2006) with three strains of Rhizobium galegae for their intrinsic resistance to different concentration of antibiotics also support the present finding. They observed good growth of Rhizobium in presence of Trimethoprim, Clindamycin in addition to Chloramphenicol, but were more susceptible to Tetracycline and Streptomycin as found in present study. Among the different rhizobia studied, maximum zone of inhibition $(34 \mathrm{~mm})$ was observed in pea rhizobia against Azithromycin $15 \mu \mathrm{g}$ followed by moong rhizobia $(36 \mathrm{~mm})$ against Tetracycline $30 \mu \mathrm{g}$. In addition to above Milicic et al., (2006) also found Rhizobium to be susceptible to a number of other antibiotics viz., Ampicillin, Gentamycin, Erythromycin, Cephalexin. In support to our study, Maatalah et al., (2002) also found gram Rhizobium to be resistant to antibiotics $\left(\mu \mathrm{g} \mathrm{ml} \mathrm{m}^{-1}\right)$ viz., Ampicillin (50), Chloramphenicol (10). They also found the Rhizobium resistant to Kanamycin (10 and 100), Nalidixic acid (50) and Streptomycin (23 and 100) whereas in present study, winged bean rhizobia were found highly susceptible to Nalidixic acid $(30 \mu \mathrm{g})$ and least susceptible to Kannamycin $(30 \mu \mathrm{g})$ and Streptomycin $(10 \mu \mathrm{g})$. All the rhizobia were found highly susceptible to Tetracycline $(30 \mu \mathrm{g})$ except winged bean and pea rhizobia. Similar results also been reported by Datta et al., (2015), who found Rhizobium phaseoli, $R$. trifolii and $R$. leguminosarum sensitive to Tetracycline $(30 \mu \mathrm{g})$. In case of winged bean isolate, it was found highly susceptible to Nalidixic acid $(30 \mu \mathrm{g})$ and least susceptible to Kanamycin $(30 \mu \mathrm{g})$, Streptomycin $(10 \mu \mathrm{g})$ resulting in an inhibition zone of 22 and $12 \mathrm{~mm}$ respectively. Sensitivity of Rhizobium isolates to antibiotics may be due to the fact that these bacteria (Rhizobium) have not been exposed to these antibiotics in natural environments Depending on the differences in antibiotic resistance pattern, this technique can be successfully employed in ecological studies particularly in the recovery and enumeration of rhizobia introduced in soil. Resistance to Chloramphenicol (5 and $10 \mu \mathrm{g} \mathrm{ml}^{-1}$ ) by lentil nodulating rhizobial isolates was reported by Jida and Assefa (2011) supporting the findings of present study where gram rhizobia was found resistant to Chloramphenicol $(15 \mu \mathrm{g})$. They also found Rhizobium to be resistant to Nalidixic acid (5 and $10 \mu \mathrm{g} \mathrm{ml}^{-1}$ ) unlike winged bean rhizobia to be highly susceptible to Nalidixic acid $(30 \mu \mathrm{g})$ in the present study. Rhizobium isolated from different crop root nodules and found resistant to different antibiotics tested in the present study might be due to the intrinsic resistance capacity of different rhizobial strains to antibiotics expressed as phenotypic characteristics. A broad variation regarding susceptibility or resistance of individual rhizobial strains to antibiotics exist in nature as discussed above. The character of resistance of rhizobial strains to antibiotics may serve as a potential tool for monitoring their competitiveness as a 'label' for nodulation and effectiveness.

\section{References}

Ali, S.F., Rawat, L.S., Meghvansi, M.K. and Mahna, S.K. 2009. Selection of stresstolerant rhizobial isolates of wild legumes growing in dry regions of Rajasthan, India. ARPN J.Agri. and Biol. Sci. 4(1):13-18.

Anjum, M.A., Zahir, A.Z., Arshad, M. and Ashraf, M. 2011. Isolation and screening of rhizobia for auxin biosynthesis and growth promotion of mung bean (Vigna radiate L.) seedlings under axenic conditions. Soil Environ. 30(1): 18-26. 
Bordeleau, L.M. and Prévost, D. 1994. Nodulation and nitrogen fixation in extreme environments. Plant and Soil. 161:115-125.

Cole, M. A. and Elkan, G. H. 1979. Multiple antibiotic resistance in Rhizobium japonicum. Appl. Environ. Microbiol. 37: 867-870.

Datta, A., Singh, R.K. and Tabassum, S. 2015. Isolation, characterization and growth of Rhizobium strains under optimum conditions for effective biofertilizer production. Int. J. Sci. Pev. Res. 32(1):199-208.

Datta, C. and Basu, P. 2000. Lndole acetic acid production by a Rhizobium species from root nodules of a leguminous shrub Cajanus cojan. Microbiol. Res.155: $123-127$.

Ehmann, A. 1977. The Van Urk-Salkowski reagent-a sensitive and specific chromogenic reagent for silica gel thinlayer chromatographic detection and identification of indole derivatives. $J$. Chromatography. 132:267-276.

Elizabeth, L.J., Watkin, A., Howleson, J.G., O'Hara, G., Ewing, M. and Best, W. 2000. Identification of tolerance to soil acidity in inoculants strains of Rhizobium leguminosarium by Trifolii. Soil Biol. and Biochem. 32: 1393-1403.

Ernstsen, A., Sandberg, G., Crozier, A. and Wheeler, C.T. 1987. Endogenous indoles and the biosynthesis and metabolism of indole-3-acetic acid in cultures of Rhizobium phaseoli. Planta. 171:422-428.

Gauri Singh, A.K. and Bamania, M. 2012. Characterization of Mesorhizobium sp. isolated from root nodules of Cicer arietinum. I. J. Agri. Sci. 2(3):142-154.

Halda-Alija, L. 2003. Identification of indole3 -acetic acid producing fresh water wet land rhizosphere bacteria associated with Juncus effuses (L.). Can. J. Microbiol. 49(12): 781-787.
Hartman, A. and N. Amarger, N. 1991.Genotipic diversity of an indigenous Rhizobium meliloti field population assessed by plasmid profiles DNA fingerprinting and insertion sequence typing. Can. J. Microbiol. 37: 600-608.

Huang, H.C. and Erickson, R.S. 2007. Effect of seed treatment with Rhizobium leguminosarum on pythium dampingoff, seedling height, root nodulation, root biomass, shoot biomass and seed yield of pea and lentil. J. Phytopathol. 155: 31-37.

Jida, M. and Assefa, F. 2011. Phenotypic and plant growth promoting characteristics of Rhizobium leguminosarum bv. viciae from lentil growing areas of Ethiopia. African J. Microbiol. Res. 5(24): 41334142.

Kapembwa, R., Mweetwa, A.M., Ngulube, M. and Yengwe, J. 2016. Morphological and biochemical characterization of soybean nodulating rhizobia indigenous to Zambia. Sustainable Agri. Res. 5(3): 84-92.

Keneni, A., Assefa, F. and Prabu, P. C. 2010. Characterization of acid and salt tolerant Rhizobial strains isolated from faba bean fields of Wollo, Northern Ethiopia. J. Agri. Sci. Tech.12:365-376.

Kucuk, C. and Cevheri, C. 2016. Indole acetic acid production by Rhizobium sp. isolated from pea (Pisum sativum L. $s p$. arvense). Turkish J. Life Sci.. 1(1): 4345.

Kumar, R.P. and Ram, R.M. 2012. Production of indole acetic acid by Rhizobium isolates from Vigna trilobata (L) Verdc. African J. Microbiol. Res. 6(27): 55365541.

Lloret, J., Bolanos, L., Lucas, M.M., Peart, J.M., Brewin, N.J., Bonilla, I. and Rivilla, R. 1995. Ionic stress and osmotic pressure induce different alternations in the LPS at a 
Rihzomeliltes stain. Appl. and Environ. Microbiol. 61: 3701-3705.

Matallah, J., Berraho, E.B., Sanjuan, J. and Lluch, C. 2002. Phenotypic characterization of rhizobia isolated from chickpea (Cicer arietinum) growing in Moroccan soils. Agronomie. 22:321-329.

Mensah, J.K., Esumeh, F., Iyamu, M. and Omoifo, C. 2006.Effects of different salt concentrations and $\mathrm{pH}$ on growth of Rhizobium sp. and a cowpea-Rhizobium association. American-Eurasian J. Agri. andEnviron. Sci. 1(3):198-202.

Milicic, B., Delic, D., Kuzmanovic, D., Stajkovic, O. and Josic, D. 2006. Intrinsic antibiotic resistance of different Bradyrhizobium japonicum and Rhizobium galegae strains. Roum. Biotechnol. Lett. 11(3): 2723-2731.

Miller, K.J. and Wood, A. 1996. Osmoadaptations by rhizosphere bacteria. Ann.Rev.Microbiol. 5: 101136.

Othman, H. and Tamimi, S.M. 2016. Characterization of rhizobia nodulating faba bean plants isolated from soils of Jordan for plant growth promoting activities and $\mathrm{N}_{2}$ fixation potential. Int. J. Adv. Res. Biol. Sci. 3(6):20-27.

Prasuna, L.M. 2014. Evolution of antibiotic resistance genes; the DNA sequence of kanamycin resistant gene from Streptococcus aureus. Ind. J. Sci. Res. 4(1): 22-24.

Rai, R. and Sen, A. 2015. Biochemical Characterization of French Bean
Associated Rhizobia found in north Bengal and Sikkim. J. Academia and Industrial Res. (JAIR). 4:10-18.

Rajpoot, P. and Panwar, K.S. 2013. Isolation and characterization oh rhizobia and their effect on Vigna radiata plant. Octa. J. Biosci. 1(1):69-76.

Satyanandanam, T., Babu, K., Rosaiah, G. and Vijaylakshmi, M. 2013. Screening of Rhizobium strains isolated from Vigna mungo native to rice fallows for the production of indole acetic acid. Int. J. Pharmacy Biol. dSci. 3(4):56-61.

Tas, E., Leinonen, P., Saano, A., Rasanen, I.A., Kaijalainen, S., Piipola, S., Hakola, S. andLindstrom, K. 1996. Assessment of competitiveness of rhizobia infecting Galega orientalis on the basis of plant yield, nodulation and strain identification by antibiotics resistance and PCR. Environ. Microbiol. 62: 529-535.

Yanni, Y.G. 1992. Performance of chickpea, lentil and lupin nodulated with indigenous or inoculated rhizobia micropartners under nitrogen, boron, cobalt and molybdenum fertilization schedules. World J. Microbiol. Biotechnol. 8: 607-613.

Zafar-ul-Hye, M., Ahmad, M. and Shahzad, S.M. 2013. Synergistic effect of rhizobia and plant growth promoting rhizobacteria on the growth and nodulation of lentil seedlings under axenic conditions. Soil Environ. 32: 7986.

\section{How to cite this article:}

Shweta Kumari, R.C. Yadav and Jha, M. N. 2018. Evaluation of Physiological Properties of Winged Bean Rhizobium and Its Comparison with Other Rhizobia. Int.J.Curr.Microbiol.App.Sci. 7(04): 3254-3264. doi: https://doi.org/10.20546/ijcmas.2018.704.369 